\title{
Enhancing the Quality of EAP Writing through Overt Teaching
}

\author{
Roselind WEE \\ Universiti Teknologi MARA, Jalan Meranek, 94300 Kota Samarahan \\ Sarawak, Malaysia \\ Tel: 60-8-267-7658Ｅ-mail: roselind@sarawak.uitm.edu.my \\ Jacqueline SIM \\ Universiti Teknologi MARA, Jalan Meranek, 94300 Kota Samarahan \\ SAarawak, Malaysia \\ Tel: 60-8-267-7661Ｅ-mail: jacqueline@sarawak.uitm.edu.my \\ Kamaruzaman JUSOFF (Corresponding author) \\ Faculty of Forestry, Universiti Putra Malaysia, Serdang 43400 Selangor. Malaysia \\ Tel: 60-3-89467176_E-mail: kjusoff@yahoo.com
}

\begin{abstract}
This paper examines how overt teaching is instrumental in reducing subject-verb agreement (SVA) errors of Malaysian EAP learners which in turn improves the quality of their writing. The researchers used overt teaching of these grammatical items, that is, SVA and investigated how this method has significantly benefitted the learners who were second year university students from different cultural and language backgrounds. Data was collected using a pre-test and a post-test. Even though the learners had spent more than a decade learning the English language since their early education, the data collected in the pre-test showed that they made gross SVA errors in their writing. Treatment in the form of overt teaching of SVA was given to the learners, after which the post-test was administered. The comparison of data of the two tests revealed significant improvements in the learners' usage of SVA which resulted in improved quality of their writing. The major findings on the learners' grammatical problems especially in SVA and their response to overt teaching prove that overt teaching enhances the quality of EAP writing produced by students.
\end{abstract}

Keywords: Overt teaching, Subject-verb agreement, Errors, EAP writing

\section{Introduction}

The dominant language in Malaysia is Bahasa Malaysia which is the medium of instruction in schools but the English language also plays an important role in the country. Therefore, students are exposed to the language at a very tender age. However, despite spending between 11 to 13 years of learning English as a second language, the Malaysian learners are still not proficient in the English language. Therefore, "teaching English language is a big challenge in this country" (Malaysia) (Nor Hashimah Jalaluddin et al., 2008). The majority of Malaysian learners have still not mastered the grammatical rules of the English Language. They have been exposed to a communicative syllabus which focuses more on communicative competence rather than grammatical competence. However, grammatical competence is a major component of communicative competence and gives the form or the structures of the language. There is no doubt that "formal grammar is an important aspect, and with all its faults, which are grievous, traditional grammar is better than no grammar at all" (Bloor, 1986). Therefore, it is not surprising that even after many years of studying English with the Malaysian communicative syllabus, they still fail to acquire high levels of grammatical accuracy. Sharifah Zakiah et al.'s (2009) study proved that the level of grammatical accuracy manifested in oral performances of Universiti Teknologi Mara (UiTM) graduates seems to be quite low.

Kroll and Schafer (quoted in Frodesen as cited in Tan, 2005) suggested that teachers should look at students' errors not simply as failures, but as windows into their minds. Shaughnessy (as cited in Tan 2005) suggested that teachers should teach students to keep a list of personal grammar trouble spots. Rei-Noguchi (as cited in Tan 2005) suggested that English language teachers should focus on just a few key grammatical issues that show up in students' language use. The data from the study done by Sharifah Zakiah et al. (2009) revealed a desperate need on the part of UiTM students to undergo further remedial help on basic grammatical rules and structures in English. It was further shown that the most frequent grammatical errors that Malaysian students often have difficulty with seem to be the most basic and most anticipated errors such as noun number, SVA and verb tense due to the structure of their first language (L1), Bahasa Malaysia. Since SVA is an area of great difficulties for the students, the researchers decided to focus on this area.

In order to improve the students' proficiency level of the English language, the researchers used overt teaching. Ellis 
(2003) pointed out that teachers need to take into account three principles when teaching grammar. First, learners need to focus on both meaning and form when learning a second language. (This is when the Malaysian communicative syllabus is lacking as it does not pay much attention to the form of the language). Secondly, learners need to notice and comprehend the grammatical forms in input or exposure. Finally, learners' awareness of grammatical forms helps them to acquire grammatical features slowly and gradually. The students' proficiency level of the English language improved significantly when the researchers used overt teaching which was proven to be effective as the subjects made fewer SVA errors in the post-test as compared to the great number of errors made in the pre-test before treatment was given. Therefore, attention to form can assist learners to move from one stage to another stage of acquisition more rapidly.

Many studies which were conducted have proven that verb forms particularly SVA is an area that poses problems to learners. Bhatia (1974) conducted an error analysis study at University of New Delhi. The subjects were second year Bachelor of Arts students aged about 17 with Hindi as their mother tongue. They wrote a 250 -word free composition for their regular class work which showed that verb forms and tense sequence made up 40 per cent of the errors and that of SVA was 20 per cent.

Vongthieres (1974) studied selected English grammatical difficulties of 30 advanced Thai students at Ohio State University. She analysed their informal essays and discovered that errors in the verb system accounted for the highest frequency of errors ( 32.4 per cent) . This was sub-divided into other categories with tenses ( 44.8 per cent) as the highest percentage and SVA came second at 20.8 per cent. Krairussamee's (1982) analysis of the errors made in the compositions writtten by 153 first year university students in Bangkok also revealed that verb form errors were errors of the highest frequencey (32.56 per cent). This was sub-divided into different categories with tense and verb forms having the highest percentage of 55.24 per cent and that of SVA coming in second at 20.42 per cent.

Elliot (1983) examined and identified errors in descriptive (non-scientific) writing of Singapore's Nanyang University graduates in science and mathematics. The 20 candidates wrote two essays of 150 words each. There was a control group of 20 candidates from University of Singapore. The situation in Singapore is similar to that in Malaysia. Learners attempt to learn the correct form of the second language (L2) in an environment where the first language (L1) and a deviant form of L2 are used. The standard form of L2 exists only in the classroom. As such, the non-standard English that is used by the majority of the population has an influence on the standard form of L2. "In Singapore, communication in English is often achieved without the grammatically correct use of verbs" (Elliot, 1983). The two groups surveyed by Elliot showed difficulty with verbs, with agreement of subject and verb, especially in the third person singular present. This situation is similar to that faced by the subjects in this present study.

Marlyna et al. (as cited in Nor Hashimah Jalaluddin et al. 2008) observed the occurrence of mistakes in SVA and copula "be". These researchers stated that "the failure of acquiring SVA form among most students is rather predictable. The absence of this structure in the Malay language has significantly deterred the students from acquiring it." Similarly, Dalrymple (as cited in Kusutani n.d.) found that Japanese students also face problems in using the copula "be" in the English language as the copula "be" is absent in sentences in Japanese. These Japanese students are not familiar with the copula "be" and SVA. In SVA, problems occur when the verb has to be inflected in the present tense to agree with the subject. The verbs must agree with the subjects for the copula "be" in the past tense and the continuous tenses. Also for the present perfect tense, the verb "have" must agree with the subjects. The findings of Marlyna et al.'s (as cited in Nor Hashimah Jalaluddin et al. 2008) research showed that 46.83 per cent of learners' mistakes were on SVA. The researchers argued that this is due to the fact that SVA is not required in the Malay Language. In additon, Bailis et al.(1994) found out that SVA is considered a common error but argued that not all students need instruction on all types of SVA errors. They found out that students who scored nine or less on their writing placement test committed more SVA errors than students who scored above that level. The results of their studies support this present support that the most frequent type of error is the general category of a verb not agreeing with its subject.

Law (2005) studied the acquisition of English SVA by Cantonese speakers and found that learners showed very obvious evidence of the influences of their first language, that is, Cantonese. It was found that these grammar errors were related to SVA including plural singular (11.31 per cent), tenses ( 31.55 per cent), negation (4.67 per cent) and interrogative (4.17 per cent) making up more than 50 per cent of the errors made. This shows that SVA is also the most difficult areas for the Cantonese learners.

Despite its difficulty for learners, SVA is one of the basic grammatical knowledge every learner must acquire in order to communicate fluently and effectively in English whether in the written or spoken form (Tan 2005). However, most Malaysian students learning English face great difficulties in this area. Sharifah Zakiah et al. (2009) recommend that teachers introduce consciousness-raising techniques to sensitize learners to the various forms and meanings of structures. Ellis and Long (as cited by Gao 2009) "found that form instruction is most effective when it is focused on raising learners' awareness of how a structure is formed, what it means, and how it it is used rather than on practising drills for accuracy". A number of studies have been conducted in the area of SVA and it has been revealed that overt teaching is effective in reducing the SVA errors made by students. Wei (2008) stressed the need for teachers' 
intervention as he believed that "without timely instruction and correction, the errors will stay". Corder (as cited by Wei 2008) stated that "sufficient input of the target language is the effective method to overcome the negative transfer of native language".

Overt teaching involves the explanation of the rules of a new structure either through the deductive (direct) approach or the inductive (discovery) approach. Direct or deductive instruction involves oral or written explanations of a given rule usually at the beginning of a lesson. In the inductive approach, the learners are provided with data which illustrate a particular grammatical structure which they need to analyze to arrive at some generalization, for instance, the students are presented with a text containing a lot of examples of SVA for which they have to identify the rule concerning that target grammatical item, in this case, SVA. The researchers in this study use both the deductive and inductive approaches in their overt teaching of SVA rules. According to Paradowski (2007), the primary task of instruction is to make clear the rule/concept to help learners grasp and internalise it in order to make it operative in their language performance.

Tan (2005) investigated the types of SVA errors found in the writing of Bachelor of Education TESL first year students and found out that overt teaching in the form of drill exercises were effective in reducing the SVA errors made. The findings from the study revealed that there was a 72.7 per cent reduction in the number of SVA errors after treatment was given indicating that the drill exercises were effective in bringing about this reduction. This study supports her findings as the subjects in this study also made significantly less SVA errors after treatment which has guided them to "understand the nature of the errors made" (Ho, 2005: 1). According to Selinker (1992), the process of making errors provides learning opportunities to learners. The subjects' violation of the SVA rules allows the researchers to explicitly help them deal with their language used in writing. Thus, this form of teaching overtly focuses on language lessons that emphasise on the learners' weaknesses and problem areas.

Andrews (2007) studied the effects of implicit and explicit instruction on simple and complex grammatical structures for adult English Language learners. This study found that teaching made a difference as both treatment groups learnt both the complex and simple forms after implicit and explicit instruction respectively. "For the simple rule, there was no significant difference between an explicit, teacher directed-instructional approach and an implicit, grammar-discovery approach" (Andrews 2007). However, for the complex rule, the explicit treatment groups showed significantly higher learning. It was suggested that teachers could spend the limited grammar-teaching time on complex structures and allowed the students to induct the simple rules themselves. Andrews (2007) remarked that this study brought to light that in an academic purpose class, especially for adult learners who can tap into L1 linguistic knowledge and cognitively process new second language (L2) forms during a presentation, an explicit approach can be considered especially for complex structures.

The grammatical errors in English essay writing among rural Malay Secondary school students in Malaysia were studied by Maros et al. (2007). The study showed that despite 6 years of learning English, the learners still had difficulty in using the correct English grammar in their writing reflected in three most frequent errors, namely, use of articles, SVA and copula "be". A large number of these errors were due to the Malay mother tongue interference. It was suggested that "remedial measures should be taken to implement approaches that could best assist students in these problematic areas" (Maros et al. 2007).

The objectives of this study are firstly, to explore SVA errors made by English for Academic Purpose (EAP) learners in their writing, and, secondly, to investigate how overt teaching has improved their grammatical competence which in turn improves their quality of writing. This study supports the claim that the quality of a piece of writing is often evaluated by the number of errors; grammatical or otherwise, that general readers see in it (Tan, 2005).

\section{Methodology}

This study involved 39 second year learners from a public university in Malaysia pursuing a three-year diploma programme. This sample size was from two different faculties, that is, the first group of nineteen students was from the Faculty of Business Studies while the other group of twenty students was from the Faculty of Accountancy. These two groups of students were chosen as the sample of this study because they had been studying together in their respective groups for the past one year, that is, two semesters. As such, they had been exposed to a similar methodology of teaching English, similar materials used by the lecturers and the same number of contact hours. This was to ensure that both groups were as similar as possible in terms of exposure to the English Language prior to the study. On top of that, these two groups of learners were taking for their first time a writing course in English for Academic Purposes (EAP) which equipped them with the necessary writing skills for completing their reports and dissertations but nevertheless, required them to have already attained an advanced proficiency level of the English language. These subjects had spent their first two semesters, that is, their first year studying proficiency-level English. They were taking the six-hour weekly EAP course taught by the two researchers when the data was collected. The ages of the sample ranged between 21 to 25 years and all of them were Bumiputeras, the native people of Malaysia. English was the third language to all of them after their mother tongue and Bahasa Malaysia, the national language of Malaysia. All these subjects have spent 
more than a decade studying the English language in schools. English was taught using the implicit way as the emphasis was on functional and conversational English.

Data for this study was collected using a pre-test and a post-test. The pre-test data was analysed to determine the types and frequency of SVA errors the subjects made in their writing. The post-test data was also analysed to determine the types and frequency of the SVA errors made after treatment of overt teaching of the targeted grammatical item, that is, SVA. Comparison was made between the results of the two tests in order to determine how overt teaching had affected the number of SVA errors made in their writing before and after the treatment.

During the pre-test, the subjects were given two pieces of reading materials of about 2,000 words on a contemporary discussive topic which the subjects were familiar with. After that, they were asked to produce a 350-word essay on the topic in one and a half hours. The subjects were advised to obtain points for their essays from the reading materials provided even though they were not limited to any number of points to include in their writing. Their essays were collected and then the SVA errors in each essay were highlighted and classified using a 2-step classification of learners' SVA errors in writing, which was an adaption of Ho's (2005) 3-step approach to errors in students' writing. According to Ho (2005:1) learners' mistakes are "systematic" and this allowed them to be classified. This 2-step approach in Table 1 identified the occurrences of the SVA errors and then each occurrence was classified according to the different SVA forms.

After identification and classification of the SVA errors in the pre-test were made, the researchers highlighted and targeted the SVA forms where the subjects had the most errors. These forms were later taught to the subjects by the two researchers. This form of teaching or treatment by way of explicit teaching was carried out over a period of two weeks comprising three sessions with each session lasting two hours. Therefore, the subjects spent a total of six hours learning the targeted SVA rules explicitly. SVA rules were explained to the subjects followed by written exercises and error correction of sample writing collected from the subjects. Wang (2008) pointed out that "teacher correction can be beneficial when errors are repeatedly made by most students". Attention was drawn to errors made in SVA and explicit explanation was given to explain why the errors occurred with reference being made to the targeted SVA grammatical rules. This form of explicit correction of the subjects' errors in SVA is similar to one of the six types of teachers' corrective feedback identified by Lyster and Ranta (as cited in Yoshida, 2008) which may prove to be effective in helping learners' internalize the target forms.

After this treatment, the post-test was conducted. The rubrics of the post-test was similar to that of the pre-test with the subjects being given another set of two reading materials of about 2,000 words on a contemporary topic which they were familiar with. After reading the materials, they were instructed to write another discussive writing based on a given topic which was related to the reading materials. The subjects were also given one and a half hours to complete their 350-word essays. Data from this post-test was analysed using the same method as data from the pre-test, that is, the targeted SVA errors were highlighted, and then categorised using the 2-step classification of learners' SVA errors in writing.

After that, data from the two tests were compared to determine if the use of overt teaching had any significant effects on the subjects' understanding and usage of the targeted forms of SVA forms in their writing.

\section{Results and discussion}

Good writing involves not only skills in the area of content, organisation or style but also the ability to produce a grammatically error-free piece of work as surface errors distract readers. According to Maxwell and Meiser (1997), SVA errors are common sentence-errors that cause learners problems in writing. Therefore, learners have to ensure that their writing is grammatically accurate. This is especially true in the case of these EAP subjects who must be equipped with the basics of writing error-free grammatically correct sentences which will not mar or distort the meaning of their writing.

"Feedback is of utmost importance to the writing process. Without individual attention and sufficient feedback on errors, improvement will not take place. We must accept the fact that L2 writing contains errors; it is our responsibility to help learners to develop strategies for self-correction and regulation. Indeed, L2 writers require and expect specific overt feedback from teachers not only on content but also on the form and structure of writing. If this feedback is not part of the instructional process, then students will be disadvantaged in improving both writing and language skills" (Myles, 2002).

Therefore, it is absolutely necessary for the researchers to provide feedback on the students' common SVA errors in order to improve their language skills and enhance their writing.

The data collected in the pre-test showed the subjects making gross SVA errors especially in the following five types of SVA forms as listed in Table 2. Of all these five types of SVA errors presented in Figure 1, the type of SVA forms where the subjects violated the SVA rule the most number of times, that is 141 times, was SVA error form 1 which requires a verb to agree with its subject. The subjects either omitted the $\sim \mathrm{s} / \sim$ es-/ ies inflection for the third person singular verbs 
such as "he mention...", "he want..." and "she check..." or they added $\sim$ s to the plural subjects such as "they needs..." and "they likes...". For the subjects to use this form correctly, their third person singular must agree with its verb by taking the $\sim$ s inflection such as "... she says...", and the plural cannot take any $\sim$ s inflection for the verb such as "...we check...".

Celce-Murcia and Larson-Freeman (1983) identified this problem on the omission of the third person singular inflection as one of the four problems on SVA forms in their checklist of troublesome cases (1999). Meanwhile, Pilleux (2003) rationalised that learners sometimes commit this type of errors when they omit the $\sim \mathrm{s}$ inflection from the third person singular verb in their attempt to make the verb agree with the singular subject like the subjects in this study using "he make..." and "it seem...". Alternatively, they also overuse the $\sim$ s inflection as plural marking by trying to "pluralise" the verbs by adding the $\sim$ s inflections to make them agree with the plural subjects such as "we starts..." and "they likes...".

In English, it is a mandatory rule that the verb must agree with the subject. A singular subject takes a singular verb whereas a plural subject takes a plural verb. Take for instance, the third person pronouns such as "he, she and it" take a singular verb with the $\sim$ s inflection as in "The boy//He/She/It eats". On the other hand, the plural subjects and pronouns such as "I, We, You and They" take the stem form of the verbs. The conditions for using the third person singular $\sim \mathrm{S} / \sim e s / \sim$ ies inflection are complicated because learners have to simultaneously identify the relevant contexts for number distinctions and manipulate the elements that affect the number agreement relationship.

Dan (2007) found that intralingual errors still play a significant role in students' writing due to students' poor command of grammar structures. First, the subject must be in a certain person and number and the predication has to be in a certain mood and tense. It is not easy to explain the rule, for example, if the lecturer tells the subject that the $\sim \mathrm{s} / \sim \mathrm{es} / \sim$ ies inflection is used in the verbs after the third person singular, this may be misleading. There are many instances when this is not so, for example, the use of questions that begins with "does". The $\sim \mathrm{s} / \sim$ es/ ies inflection precedes the subjects and the stem forms follow the subjects, for example, "Does he copy?" The main verbs that come after "does not" in the negative forms are also in the infinitive, for example, "He does not copy." For the third person singular present tense that comes after the use of a modal auxiliary, the infinitive form is also used such as "She can write." If lecturers give the wrong explanations or make contradictory statements, the learners may get even more confused. In English, there are many exceptions to the general rule such as the use in question and negative forms as well as its use after the modal verbs. In addition, the influence of the mother tongue and the national language which does not require any marking of person or number makes it difficult for the subjects to master the SVA forms in English. The findings in this study support George (1972),

"In practice, the stem $+s$ " form gives a lot of trouble to teachers and learners in classes where the learner's mother tongue does not have verb inflections. Though the learner experiences its occurrence very frequently and it is drilled to excess, its lack of significance often prevents its acceptance into the learner's permanent memory store as a third person singular subject association."

In the case of the subjects who speak mainly the Malay language which is the medium of instruction in Malaysia, there is no SVA form in the language, for example, "Ali pergi ke pasar" (Ali go to the market) and "Mereka pergi ke pasar" (They go to the market). The stem forms of the verbs are often used in all contexts regardless of tense or number. "Most Asian languages use the stem forms of nouns and verbs in all contexts so that both the inflections of English and the concepts behind them seem to convey redundant information" (George, 1972). This was further supported by Nair (1990) who stated, "In English, the insertion or non-insertion of $\sim$ s to show number in the verb structure is redundant. To the Malay student, this rule in English does not hinder his communicative ability to any large extent." This explains why the subjects in this study made gross errors in their use of the SVA forms as during the process of writing, interference from the mother tongue or the national language which is the medium of instruction in schools, that is, the Malay language, affected how they used the SVA forms correctly.

It was noticed that the subjects often used the stem forms of the verbs in order to simplify the target language rules. This reduced the linguistic burden or learning load. The subjects used this simplification process that increased the generality of rules by extending their range of application and dropping rules of limited applicability. They tried to construct an optimum grammar, that is, grammar in which the fewest number of rules did the maximum amount of work. Thus, it is not surprising that most of them did not master SVA in English. The rule for the third person singular present tense in English is redundant and unnecessary for communication since it does not affect the meaning of the sentence if it is omitted. So, this rule is often not applied by ESL learners. Richards (1985) pointed out that overgeneralisation may be the result of the learners reducing their linguistic burden. With the omission of the third person $\sim \mathrm{S}$ inflection, overgeneralisation removes the necessity for concord, thus relieving the "learner of considerable effort." Duskova (1969) explains,

"since all grammatical persons take the same zero verbal ending except the third person singular in the present tense, which is the only verbal form with a distinctive verbal personal ending (apart from the anomalous "am") omission of 
the $\sim \mathrm{s}$ in the third person singular may be accounted for by the heavy pressure for all the other endingless forms".

Wei (2008) pointed out that some learners may turn to learning strategies such as overgeneralisation, simplification, incomplete rule application and inadequate declarative knowledge of L2.

In addition, it was not easy for the subjects to master the use of the copula, the verb "be". They made mistakes like "The lecturer are...", "Plagiarism are...", "Students is..." and "The problems is..." The "be" verb was often omitted and if it was used, it was not done correctly as is shown by the examples given. The verb "be' is difficult to use because it exits in eight different forms (am, is, are, was, were, be, been and being). Five of these forms do not resemble the stem form and it must agree in person, number and tense with the subject. Thus, many students are confused with its use as there are various conditions to be met to enable the appropriate forms to be used .For the verb "have", it has three forms, "have, has and had". "Have" is often inflected in the third person singular present tense and becomes "has" but this inflected form is often rejected for "have" which is the stem form. Ho (1973) pointed out that "lack of subject-verb agreement often involves forms of "be" and "have" functioning either as full or auxiliary verbs. This has been traced to the fact that both have irregular forms." In the present study, the subjects came up with errors like, "Student have..." "It have...," and "They has..."

Here, the subjects also made numerous errors in the concord of number between subject and verb which according to Pilleux (2003), has been considered as the most important type of concord in English. The subject of the sentence determines the concord, and hence, the verb forms that allow a distinction between singular and plural forms are dependent on whether the subject is singular or plural. The subjects were unable to use this form of SVA correctly and they made errors such as "lecturer mark...", “...student speak...", “...students writes..." and "...people says...”. It is important for language teachers and lecturers to teach the use of the third person singular in the simple present tense. However, they must be aware of the danger of hypercorrection, for example, overemphasis and drilling intensively this usage may cause students to use it inappropriately in cases where it is incorrect to do so, for example the insertion of " $\sim$ / es $\sim$ ies" to verbs after the plural pronouns or nouns, for example, "They goes to school by school bus." and "The passengers likes to ride in his taxi." (Wee, 1995). According to Wei (2008), "incorrect teaching method can prevent successful second language learning.". Therefore, the problematic areas need to be taught correctly to ensure students' mastery of the correct forms. Wiener (1981) suggested that

"those who violate the system of agreement will require instruction in the differences between the $\sim \mathrm{S} / \sim \mathrm{e} / \sim$ ies inflection for the verb and for the noun, and will need to develop a sense of when to use the $\sim \mathrm{s}$ inflection at the end of the verbs. A good syllabus provides instruction in subject-verb recognition so you have a foundation in key grammatical concepts upon which to build."

The results of the study reveal that these subjects have learnt the targeted SVA rules after undergoing overt teaching as can be seen in Figure 2 (indicated by 1). Their post-test essays showed a very significant decrease in the number of SVA errors found in verbs that do not agree with the subject. In the pre-test, the subjects made 141 errors but after overt teaching of this SVA form, the subjects made only 48 errors in the post-test. Nevertheless, in comparison to the other SVA error forms, the subjects still had more errors in this form than the other SVA forms after overt teaching.

Obviously, overt teaching that has been given by the researchers has proven effective in reducing the number of errors made in their post-test essays as compared to errors of the same form in the pre-test. Similarly, Richards, Gallo, and Renandya (2001:55) discovered that "direct grammar teaching would result in more accurate language use". This was based on their survey conducted on teachers of the English language who were prepared to teach the language in the communicative way but nevertheless also believed in the positive impact of teaching grammar directly. Loewen (as cited in Yoshida, 2008) who examined classroom studies on uptake of corrective feedback by teachers found that the learners responded positively to feedback provided by the teachers leading to more successful uptakes. Scott (2008) argued that language teachers are responsible to provide learners with feedback on their errors even though the level of the learners' language uptake varied with different corrective feedback. He maintained that this form of explicit and intentional correction which required them to "retrieve the target language form" will benefit the learners. Gao (2009) pointed out that "focus on form is practical and effective in college English teaching and learning in improving the students and it should be applied in college English teaching and learning to improve students' accuracy as well as fluency". Figure 3 shows a comparison of the frequency of errors made by the subjects in their pre-test and post-test essays.

The SVA error form 2 on the use of "One of..." requires the verb to agree with its subject - subject word - and not with the subject that is near to it as in "One of the reasons is..." and "One of the students is...". This form of errors appeared eight times in the subjects' pre-test essays but after the overt treatment, they appeared only twice in the post-test. Biber et al. (1999) explained that based on the Principle of Proximity, there is a strong tendency for the verb to agree with the nearest noun or pronoun even if it is not the head of the subject noun phrase. Therefore, if we were to look at the subjects' incorrect sentences such as "One of the students are ..." or "One of the factors are...", there was the tendency to choose "are" to agree with the noun closest to it, that is, in this case, "students" and "factors". 
This rule of proximity also applies to the use of "either...or "and "neither...nor" as shown in the SVA errors form 3. There were three instances of the subjects making errors with the use of this form. Take for instance, the subjects' errors in their pre-test: "Neither the junior students nor the senior student have..." and "Either the lecturer or the students checks...". Both had SVA errors because their verbs should agree with the nearest subjects. However, after explicit teaching of this SVA form, the post-test did not record any errors of this nature any more.

Most of the subjects appeared to have prior knowledge of some forms of SVA as could be seen from the sentences they constructed in the pre-test although other SVA forms proved to be challenging for these subjects. This was where they made the most number of errors. The pre-test recorded thirteen errors in the use of determiners that needed a plural verb with countable subjects such as "All...", "Some...", "A lot of...", "The majority...", "Plenty of...", "Many of..." and "Half of..." indicated as 4. The subjects either used a singular verb with plural subjects as in "All the students needs..." or a plural verb with uncountable subjects such as "All the information are...". There were also 12 errors in the use of existential sentences as represented by 5 . These sentences began with "There..." in the pre-test as could be seen in some of the subjects' essays such as "There is a few solution..." and "There are information...". In these cases, the verb which comes before the subject must be in agreement with it. Pilleux (2003) opined that phrases such as "a lot" and "lots of" in existential "there is..." or "there are..." could be problematic for some learners. However, it must be noted that after teaching these forms explicitly, the subjects' post-test did not record any errors with the use of the determiners such as "All...", "Some...", "A lot of...", "The majority...", "Plenty of...", "Many of..." and "Half of...", whereas for the existential sentences, there was only one error recorded.

It is clear that overt teaching of grammatical structures has important pedagogical implications as it draws learners' attention to the formal properties of the target language and helps them to perceive and understand features explained which will otherwise go unnoticed and unheeded. Learners who can notice and understand the targeted grammatical items can outperform those who are unable to do so. Grammar instruction makes learners realize their lack of competency and prevents fossilization in their learning. Fossilizable linguistic phenomena are linguistic items, rules and subsystems which learners tend to keep in their interlanguage (IL) regardless of their age or the amount of explanation or instruction they receive in the target language. Therefore, the teaching of grammar helps learners to modify their erroneous hypotheses and contribute to addition of new rules and confirmation of correct ones. (Paradowski, 2007). Selinker (as cited in Wang, 2008) described a learner's language as an “'interlanguage' or a 'between language' which exhibits an increasing proximity to L2. The approximation of IL to L2 is dynamic, often fluctuating process, influenced by changes about and how to use L2, as well as transfer of and hypotheses based on L1 structure applied to L2". Thus, in this study, we find the learners' IL moving closer towards the target language. Paradowski (2007) stated that "explicit teaching of grammatical forms makes learners realize that they have not mastered the whole target language (TL) system and helps them stay open to the development and restructuring of their interlanguage. They are made to remember structures". In addition, Paradowski (2007) pointed out that timely activities and corrections within explicit instruction enables learners to develop greater accuracy in the use of subsequent use of grammatical forms and structures. This is substantiated by this study which shows that the students made fewer errors in SVA after the overt teaching of these forms.

\section{Conclusion}

From the findings above, it can be concluded that overt teaching of the five SVA forms has greatly benefitted the subjects. Comparison of the data from the subjects' pre-test and post-test shows a drastic decrease in the frequency of errors in the targeted SVA error forms after overt teaching. It implies that the subjects had learnt the targeted SVA rules as they made improvements in the usage of these common SVA forms which made up the bulk of SVA forms in their essays. This has also improved the quality of their writing.

Teaching and learning can become intentional and purposeful with overt teaching when lecturers can explicitly focus on their learners' weaknesses. Teachers and lecturers should realize that is their responsibility to give due focus on those areas that students face problems and need reinforcement. In the case of SVA, the language lecturer can explain the concept of singularity and plurality in nouns by pointing out the differences in sentences such as "The student copies." and "The students copy." This overt teaching will enable the students to understand the concept of SVA better. The lecturer also should make the students realise that there are plural nouns that do not end with the $\sim \mathrm{s} / \sim \mathrm{e} / \sim$ ies inflection such as "children, mice, geese, teeth and feet." Explanations should be given that plural nouns that end with the $\sim \mathrm{s} / \sim \mathrm{e} / \sim$ ies inflections and those that do not do so require the stem-form verbs after them in the simple present tense. On the other hand, singular nouns are not inflected but they still require the $\sim \mathrm{s} / \sim \mathrm{e} / \sim$ ies inflection for the verbs that come after them in the simple present tense. This concept of agreement has to be established in the students' mind and they must realize that no matter how far the subject is separated from the verb, this rule of SVA must be applied.

The findings have led the researchers to conclude that overt teaching of problematic grammatical items be emphasized. It is recommended that teachers or lecturers identify the grammatical problems early in the semester so that any remedial work or explicit teaching can take place early. It is advisable for the teachers and lecturers to check their 
students' prior knowledge of language structures so that they have an idea of the proficiency level of their students and know which areas to focus on.

Language input plays a prominant role in language acquisition so language teachers have to ensure that optimal input which learners can convert to intake is provided. Therefore, it is recommended that explicit grammar instruction with a focus on target language grammatical items be incorporated into the writing class. Overt corrective feedback can be given by supplying explicit explanation for the errors made. By drawing the learners' attention to the targeted grammatical items to be taught, the learners can acquire these items slowly which they can eventually apply to their writing. The reduction of gross grammatical errors made by learners inevitably improves the quality of writing.

\section{References}

Andrews, Karen L. Ziemer. (2007). The effects of implicit and explicit instruction on simple and complex grammatical structures for adult English Language learners. TESL-EJ. 11/ 2.

Bailis, Larry, Kreitche, C. and Belle, C. L. (1994). Teachers' study shows subject-verb agreement most frequent problem.: http://faculty.ccp.edu/dept/viewpoints/jde/writerr.htm. Accessed April 8, 2009.

Bhatia, Aban Tavadia. (1974). An error analysis of students' compositions. IRAL. 12/4.

Biber, D., Johansson, S., Leech, G., Conrad, S. and Finegan, E. (1999). Subject-verb agreement: www.gsu.edu/ eslhpb/grammar/lecture_9/sva.htm. Accessed April 4, 2009.

Bloor, Thomas. (1986). What do language students know about grammar? British Journal of Language Teaching, 24/3 157-162: http://www.phon.ucl.uk/home/click/ec/ha\%zpla;/bjlt1986.doc. Accessed May 12, 2009.

Celce-Murcia, M. and Larsen-Freeman, D. (1983). The grammar book: An ESL/EFL teacher's course. Rowley: Newbury House Publishers, Inc.

Dan, He. (2007). On error analysis from the perspective of Interlanguage Theory: http://eng.hzu.edu.cn. Accessed July 3, 2009.

Duskova, Libuse. (1969). On sources of errors in foreign language learning. IRAL, 7/1.

Elliot, Annie B. (1983). Errors in English. Singapore: Singapore University Press.

Ellis, Rod. (2003). Becoming grammatical. Lateral Communications: http://www.impactseries.com/grammar/becoming.html. Accessed July 7, 2009.

Gao, Sixia. (2009). Focus on Form in College English Teaching. English Language Teaching 2/ 2: www. ccsnet.org/journal.html. Accessed July 3, 2009.

George, H.V. (1972). Common errors in language learning. Rowley, Mass.: Newbury House.

Ho, Caroline Mei Lin. (2005). Exploring errors in grammar. Singapore: Pearson Education South Asia Pte Ltd.

Ho, Wah Kam. (1973). An investigation of errors in English composition of some pre-university students in Singapore with suggestions for the teaching of English. RELC Journal 4.

Krairussamee, Pornthip. (1982). Teaching English as a foreign language in Thailand: A survey of the relation between students' grammatical problems and their teachers' methodology. Doctoral dissertation. U.S.A.:University of Kansas.

Kusutani. Sayuri. (n.d.). The English copula be: Japanese learners' confusion: http://web1.hpu.edu/images/GraduateStudies/TESL_WPS/04Kusutani_Syntax_a17235.pdf. Accessed June 5, 2009.

Law, Mei Han, Crystal. (2005). The acquisition of English subject verb agreement by Cantonese speakers. Master thesis, Hong Kong: The University of Hong Kong.

Maros, M., Tan Kim Hua and Khazriyati Saluhiddin. (2007). Interference in learning English: Grammatical errors in English essay writing among rural Malay secondary school students in Malaysia. Jurnal e-Bangi. 2/2.

Maxwell and Meiser. (1997). Writing: The conventions of writing: http://www.sasked.gov.sk.ca/docs/xla/ela15c5.html. Accessed April 8, 2009.

Myles, Johanne Myles. (2002). Second Language Writing and Research: The Writing Process and Error Analysis in Student Texts. TESL-EJ 6/2: http://www-writing.berkeley.edu/TESL-EJ/ej22/a1.html. Accessed June 16, 2009.

Nair, Padmanabhan. (1990). An analysis of errors in the English compositions of Malay students in Malaysian secondary schools. Master. thesis, Kuala Lumpur: Universiti Malaya.

Nor Hashimah Jalaluddin, Norsimah, M. A. and Kesumawati, A. B. (2008). The mastery of English Language among lower secondary school students in Malaysia: A Linguistic Analysis. European Journal of Social Sciences. 7/2: http://www.eurpjournals.com/ejcs-7-2-09pdf. Accessed May 12, 2009.

Paradowski, Michael B. (2007) Exploring the L1/L2 Interface: A Study of Polish Advanced EFL learners. Institute of 
English Studies. University of Warsaw, 64-85.

Pilleux, K. D. (2003). Subject-verb concord: Not just a second language acquisition issue: http://oak.cats.ohiou.edu/1kw382698/671\%20Final2. Accessed April 10, 2009.

Richards, Gallo J.C., P.B. \& Renandya, W.A. (2001). Exploring teachers' beliefs and the processes of change. PAC Journal, 1,1, 41-58.

Richards, Jack. C. (1985). The context of language teaching. Cambridge: Cambridge University Press.

Scott, Edurne. (2008). Corrective feedback in the language classroom: How to best point out language mistakes:.http://languagestudy.suite101.com/article.cfm/corrective_feedback_in_the_language_classroom\#ixzz0HSDtR yKm\&A. Accessed June 5, 2009.

Selinker, L. (1992). Rediscovering language. Essex:Longman Group UK Limited.

Sharifah Zakiah Wan Hassan, Hakim, S.F., Mahdalela, R., John, F. N., Sueb, I., Johnny A. and Kamaruzaman, J. (2009). The communicative ability of Universiti Teknologi Mara Sarawak's graduates. English Language Teaching 2/2: www.ccsenet.org/journal.html.

Accessed July 3, 2009.

Tan, Aig Bee. (2005) The use of drill exercises in helping students reduce subject-verb agreement errors in academic writing: A case study in IPBA. Jurnal. IPBA. 3/2.

Vongthieres, Siriporn. (1974). A pedagogical study of selected English grammatical difficulties of advanced Thai students. Doctoral dissertation. The Ohio State University.

Wang, Ping. (2008). Exploring errors in target language learning and use. Practice Meets Theory English Language Learning 1/2.: www.ccsenet.org/journal.html. Accessed July 3, 2009.

Wee, Roselind. (1995). Types of verb-form errors made by Sarawakian Malay ESL students. Master thesis. Kuala Lumpur: Universiti Malaya.

Wei, Xueping. (2008). Implication of IL Fossilization in Second Language Acquisition. English Language Teaching 1/ 1: www.ccsenet.org/journal.html. Accessed July 3, 2009.

Wiener, Harvey, S. (1981). The writing room-A resource book for teachers of English. Oxford: Oxford University Press.

Yoshida, Reiko. (2008). Overt and covert participation of learners in Japanese language classrooms. Doctoral dissertation. University of New South http://unsworks.unsw.edu.au/vital/access/services/Download/unsworks:2151/SOURCE2?view=true.

Accessed June 5, 2009.

Table 1. 2-step Classification of Learners' SVA Errors in Writing

\begin{tabular}{|c|c|}
\hline Identification of Errors & Classification of SVA Error Forms \\
\hline & \\
\hline & \\
\hline
\end{tabular}

Table 2. Classification of SVA Error Forms in Subjects' Writing

\begin{tabular}{|c|l|}
\hline No. & \multicolumn{1}{|c|}{ Classification of SVA Error Forms } \\
\hline 1 & A verb agrees with the subject, and concord of number \\
\hline 2 & $\begin{array}{l}\text { A verb agrees with its subject -subject word- and not with the subject near it } \\
\text { as in "One of..." }\end{array}$ \\
\hline 3 & Subjects joined by "either...or" and "neither...nor" \\
\hline 4 & $\begin{array}{l}\text { Using a plural verb with a countable subject. "All...", "Some...", "A lot } \\
\text { of ...", "Lots of...", "The majority...., "Plenty of...", "Many of..." and } \\
\text { "Half of..." }\end{array}$ \\
\hline 5 & $\begin{array}{l}\text { A verb agrees with the subject when an existential sentence begins with the } \\
\text { word "There...". }\end{array}$ \\
\hline
\end{tabular}




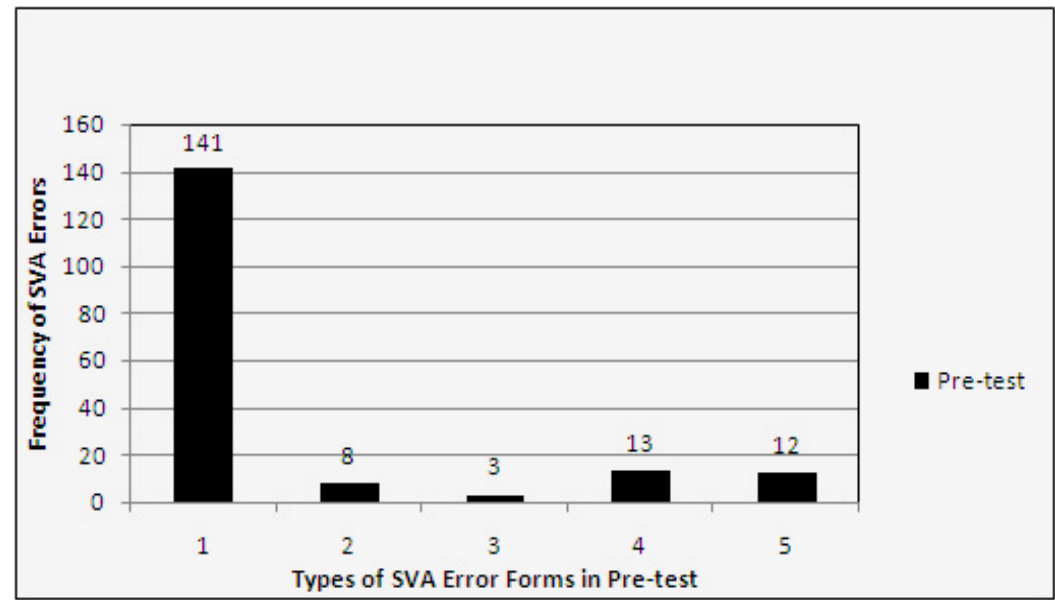

Figure 1. Frequencies and Types of Subjects' SVA Errors in the Pre-test

Legend:

1: A verb agrees with the subject, and concord of number

2: The verb agrees with its subject -subject word- and not with the subject near it as in "One of..."

3: Subjects joined by "either ...or..."and "neither...nor..."

4: Determiners that use a plural verb with countable subjects such as "All...", "Some...", "A lot of...", "The majority...", "Plenty of...", "Many of..." and "Half of...".

5: A verb agrees with the subject when an existential sentence begins with "There...", The subject comes after the verb.

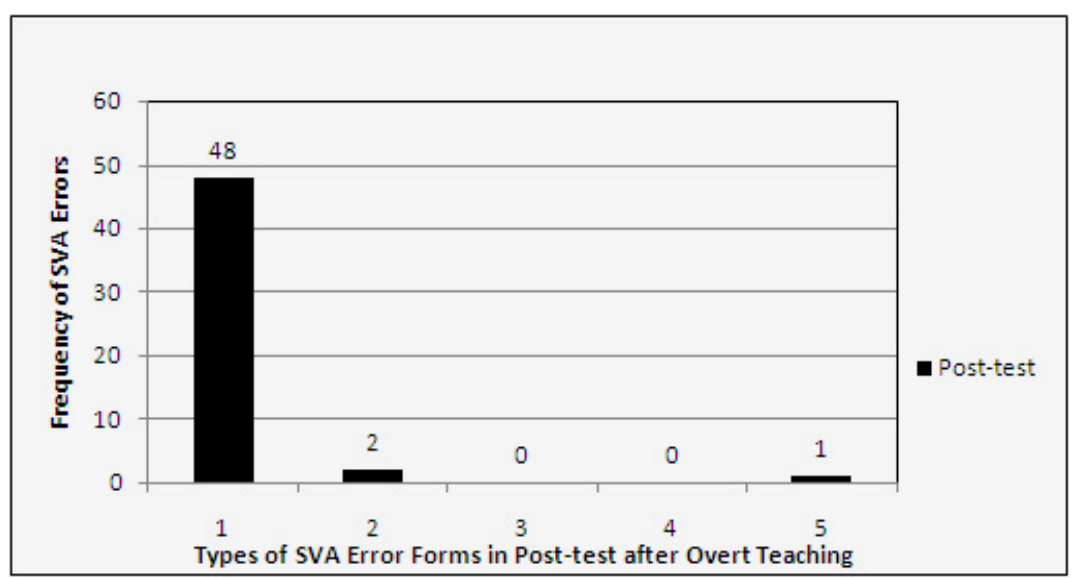

Figure 2. Frequencies and Types of Subjects' SVA Errors in the Post-test

Legend:

1: A verb agrees with the subject, and concord of number

2: The verb agrees with its subject -subject word- and not with the subject near it as in "One of..."

3: Subjects joined by "either ...or..."and "neither...nor..."

4: Determiners that use a plural verb with countable subjects such as "All...", "Some...", "A lot of...", "The majority...", "Plenty of...", "Many of..." and "Half of...".

5: A verb agrees with the subject when an existential sentence begins with "There...", The subject comes after the verb. 


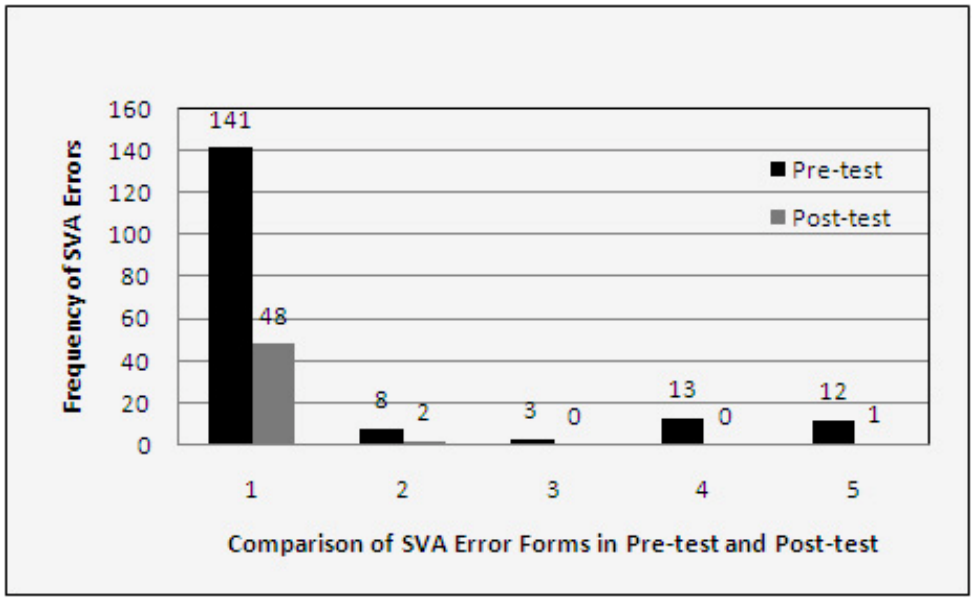

Figure 3. Comparison of Frequencies and Types of Subjects' SVA Errors in the Pre-test and Post-test after Overt Teaching

\section{Legend:}

1: A verb agrees with the subject, and concord of number

2: The verb agrees with its subject-subject word- and not with the subject near it as in "One of..."

3: Subjects joined by "either ...or..." and "neither...nor..."

4: Determiners that use a plural verb with countable subjects such as "All...", "Some...", "A lot of...", "The majority...", "Plenty of...", "Many of..." and "Half of...".

5: A verb agrees with the subject when an existential sentence begins with "There...", The subject comes after the verb. 